\title{
Pediatric open globe injury in left-behind children treated by pars plana vitrectomy in China
}

\author{
Xiaonan Zhuang", Rui Jiang", Gezhi Xu, Zhongcui Sun \\ Department of Ophthalmology, Eye and ENT Hospital of Fudan University, Shanghai, China \\ Contributions: (I) Conception and design: X Zhuang, Z Sun; (II) Administrative support: G Xu, Z Sun; (III) Provision of study materials or patients: R \\ Jiang, Z Sun; (IV) Collection and assembly of data: All authors; (V) Data analysis and interpretation: X Zhuang; (VI) Manuscript writing: All authors; \\ (VII) Final approval of manuscript: All authors. \\ \#These authors contributed equally to this work. \\ Correspondence to: Zhongcui Sun. Department of Ophthalmology, Eye and ENT Hospital of Fudan University, 83 Fenyang Road, Shanghai 200031, \\ China. Email: drsunzhongcui@126.com.
}

Background: To analyze the clinical features of pediatric open globe injury (OGI) in left-behind children (LBC) and in non-left-behind children (non-LBC) prospectively.

Methods: Patients diagnosed with OGI were included and divided into 2 groups: LBC and non-LBC. A complete ophthalmological examination was performed. Primary wound repair was completed within 8 hours from initial administration. Pars plana vitrectomy (PPV) was subsequently performed for retained intraocular foreign body (IOFB), endophthalmitis, retinal detachment, or non-clearing vitreous hemorrhage. Results: A total of 96 patients (4 to 15 years old) were recruited, including 54 LBC and 42 non-LBC. Rupture of the eyeball $(\mathrm{P}<0.001)$, endophthalmitis $(\mathrm{P}<0.001)$, primary hospitalization time $(\mathrm{PHT})$ over 24 hours ( $\mathrm{PHT}>24 \mathrm{~h})(\mathrm{P}=0.016)$, traumatic cataract $(\mathrm{P}=0.013)$, vitreous hemorrhage $(\mathrm{P}=0.040)$, numbers of surgeries $(\mathrm{P}<0.001)$, and lower OTS scores and grades $(\mathrm{P}<0.001)$ predisposed patients to poorer final visual acuity (VA). Compared with non-LBC, LBC were significantly younger $(\mathrm{P}<0.001)$, had lower OTS scores $(\mathrm{P}=0.020)$, had longer PHT $(\mathrm{P}<0.001)$, and worse baseline $(\mathrm{P}=0.011)$ and final VA $(\mathrm{P}<0.001)$. The 3 most common injury sources were pencils (20 cases, 20.8\%), knives (11 cases, $11.5 \%$ ), and iron wire (7 cases, $7.3 \%$ ). Pencils were the major injury source for IOFB (14 cases, 53.8\%). LBC were significantly more likely to be injured by instruments which should be routinely kept away from children $(\mathrm{P}=0.009)$.

Conclusions: The prognosis of pediatric OGI was worse in LBC than in non-LBC. It is necessary to improve the guardianship of LBC. Many tragedies may be avoided if adult instruments are properly stored and if children are educated to properly use writing devices.

Keywords: Pediatric open globe injury (OGI); left-behind children (LBC); pars plana vitrectomy (PPV); injury source

Submitted Mar 18, 2021. Accepted for publication Apr 29, 2021.

doi: $10.21037 / \mathrm{tp}-21-162$

View this article at: http://dx.doi.org/10.21037/tp-21-162

\section{Introduction}

Pediatric ocular trauma is an important cause of visual loss. Six million children experience an episode of ocular trauma every year $(1,2)$. Five percent of injured children (approximately 280,000) require hospital admission (1), and one-fourth of them suffer an open globe injury (OGI) (3). While ocular trauma is rarely fatal, wounded children have to live with visual impairment throughout their lives. Ocular trauma also places a significant socioeconomic burden on their families (4). However, $90 \%$ of pediatric trauma is preventable (5).

Caregivers are responsible for protecting children from hazardous behaviors. However, it was estimated that 61 million children in China were left behind in rural areas and had insufficient tutelage by their parents who migrated 
to big cities for higher incomes and better education opportunities (6). These children are termed as left-behind children (LBC) $(2,7)$. The growing number of LBC leads to a variety of social problems and draws increasing attention from the socialists and the governments (8). Compared with children living with their parents (non-LBC), LBC have worse school performance (9), worse physical health (10), poorer behavior $(11,12)$, and a higher risk of injury $(11,12)$.

The present study enrolled a consecutive series of children with OGI treated by vitrectomies. The aim of this study was to: (I) describe the etiologies and risk factors of pediatric OGI; (II) compare LBC with non-LBC in terms of clinical features and visual prognosis; and (III) make suggestions for the prevention of pediatric OGI.

We present the following article in accordance with the STROBE reporting checklist (available at http://dx.doi. org/10.21037/tp-21-162).

\section{Methods}

\section{Patients}

This was a prospective case series of 96 consecutive OGI children seen at the Eye and Ears, Nose, and Throat (ENT) Hospital, Fudan University, Shanghai, China. All the patients were diagnosed and operated on between June 2015 and June 2019. Permission for medical record review was obtained from the institutional review board (IRB) of the hospital. This study was conducted in accordance with the ethical standards stated in the Declaration of Helsinki (as revised in 2013) and was approved by the IRB/ Ethics Committee of the Eye and ENT Hospital of Fudan University (NO. KJ2009-16). Informed consent for the research was obtained from all the guardians.

All children included in this study were treated by pars plana vitrectomy (PPV). Exclusion criteria included age over 18 years old, close ocular trauma, history of eye diseases or intraocular surgeries, hereditary eye diseases, congenital dysplasia of the eyeball or the orbit, or follow-up less than 12 months.

\section{Definition of $L B C$ and non- $L B C$}

According to previous studies $(2,7)$, LBC were defined as "children under 18 who have been left behind at their original residence while one or both parents migrate into other places for work and have been not living together with them for at least six months". Non-LBC were defined as "children under 18 who live with both parents at their original residence" $(2,7)$.

\section{Preoperative examinations}

All children underwent a group of bilateral ophthalmic examinations, including slit lamp biomicroscopy, indirect ophthalmoscopy, and intraocular pressure. Computed tomography (CT) was performed if an intraocular foreign body (IOFB) was suspected. Visual acuity (VA) was measured using the Snellen E chart. Based on the system for classifying mechanical injuries of the eye (13), the zone of injury was defined by the location of the most posterior aspect of the ocular laceration. Younger children might be frightened and might not cooperate at first. They were placed in a quiet room with their caregivers who tried to soothe the children along with the ophthalmologist and the nurse. Examination was not performed until the children calmed down and cooperated with the procedures.

\section{Categories of injury sources}

Many daily instruments might be harmful to children. In the present study, injury sources were divided into 2 groups. (I) Children's instruments: some ordinary harmless devices such as stationary or toys, including pencils, badminton, basketball, compasses, football, plastic sticks, and rulers etc. (II) Adult instruments: some dangerous or sharp tools which should be routinely prohibited from children might be occasionally misplaced and taken by children, such as knives, iron wire, needle, scissors, wooden stick, iron nail, toothpick, stone, branch, car accident, firecracker, glasses, iron scrap, and syringe etc.

\section{Ocular Trauma Score (OTS)}

The OTS, described by Kuhn et al. (14), is a simplified categorical system for standardized assessment and predicting visual prognosis in ocular trauma, suitable for both children and adults. Six baseline variables, including VA, rupture, endophthalmitis, perforating injury, retinal detachment, and afferent pupillary defect, were summated and converted into 5 OTS grades. Each OTS grade projected the probabilities of a range of visual outcomes.

\section{Surgical indications and procedures}

All injuries had primary wound repair within 8 hours 
from the initial administration. Intravenous antibiotics (ceftazidime, $30 \mathrm{mg} / \mathrm{kg}$, twice per day) before and after surgery were used if endophthalmitis was highly suspected. PPV was considered for 1 of the 4 complications, including (I) retained intraocular foreign body (IOFB), (II) endophthalmitis, (III) retinal detachment, and (IV) nonclearing vitreous hemorrhage for 1 week.

Surgeries were performed under general anesthesia. The 23-gauge PPVs (Constellation, Alcon Laboratories Inc., Fort Worth, TX) were performed by Z.S. or R.J. During surgery, posterior vitreous detachment was induced and the posterior hyaloid was removed. The peripheral retina was examined with scleral depression for possible lesions. Eyes with dense cataracts (either traumatic cataract or complicated cataract by intraocular inflammation or hemorrhage) were treated by phacoemulsification (Constellation). Implantation of foldable intraocular lens (IOL) (AcrySof, Alcon Laboratories Inc.) was not performed in the one-stage operation but was considered 1-2 months later, depending on the retinal structure. Amblyopia treatment was carried out before and after IOL implantation. Eyes with endophthalmitis were given intraocular antibiotics $(0.8 \mathrm{mg} / \mathrm{mL} \times 0.1 \mathrm{~mL}$ norvancomycin and $2.25 \mathrm{mg} / \mathrm{mL} \times 0.1 \mathrm{~mL}$ ceftazidime). In cases of giant retinal breaks, retinal detachment, severe endophthalmitis, or marked ciliary body fibrosis, intraocular silicone oil tamponade was performed. The silicone oil was not removed until stable retinal attachment was achieved. If the retina remained detached or re-detached during the surgery, silicone oil tamponade was performed once more. IOFBs were removed with 18-gauge IOFB forceps (nonmagnetic IOFB) or with an intraocular magnet (magnetic IOFB) through the corneal or scleral wound.

\section{Statistical analysis}

Statistical analyses were performed using SPSS 20.0 (IBM Corp, Armonk, NY, USA). Multiple linear regression analysis was used to select possible preoperative conditions that significantly influenced the visual prognosis. Comparisons of age, VA, OTS scores, or primary hospitalization time (PHT) between LBC and non-LBC were analyzed by the Mann-Whitney $U$ test. The chi-square test was used to compare zones of injury, the number of surgeries, silicone oil tamponade, cataract removal, IOL implantation, and injury sources between LBC and non-LBC. The Wilcoxon signed ranks test was used to compare preoperative and postoperative VA. The nonparametric Spearman's test was used for the establishment of correlations.

\section{Results}

A total of 96 children were enrolled, including 76 boys and 20 girls. Their mean age was $9.3 \pm 3.5$ years old (4 to 15 years old), and the mean follow-up time was $17.5 \pm$ 4.7 months (13 to 33 months). All children had unilateral eye injuries (51 OD and 45 OS). Zone 1, 2, and 3 injuries were found in $25(26.0 \%), 34(35.4 \%)$, and 37 (38.5\%) patients, respectively. Hyphema was found in $24(25.0 \%)$ patients, traumatic cataract in $65(67.7 \%)$ patients, IOFB in $26(27.1 \%)$ patients, endophthalmitis in $58(60.4 \%)$ patients, retinal detachment in $30(31.3 \%)$ patients, and vitreous hemorrhage in 33 (34.3\%) patients. Rupture of the eyeball $(\mathrm{P}<0.001)$, endophthalmitis $(\mathrm{P}<0.001)$, $\mathrm{PHT}$ over 24 hours $(\mathrm{PHT}>24 \mathrm{~h})(\mathrm{P}=0.016)$, traumatic cataract $(\mathrm{P}=0.013)$, vitreous hemorrhage $(\mathrm{P}=0.040)$ (Figure 1), numbers of surgeries $(\mathrm{P}<0.001)$, and lower OTS scores and grades $(\mathrm{P}<0.001)$ were correlated with poorer final VA.

A total of 54 patients were LBC and 42 were nonLBC. Demographic features are summarized in Table 1 and Figure 2. The mean ages of LBC and non-LBC were $8.1 \pm 3.3$ years old and $10.8 \pm 3.1$ years old, respectively. LBC were significantly younger than non-LBC $(\mathrm{P}<0.001)$ (Figure $2 A)$. OTS scores of LBC $(54.0 \pm 16.7)$ were significantly lower than those of non-LBC $(61.1 \pm 16.6)$ $(\mathrm{P}=0.020)$ (Figure $2 B)$. For both LBC and non-LBC, lower OTS scores and grades were correlated with poorer final VA $(\mathrm{P}<0.001)$.

PHT varied greatly, from less than 1 hour to almost

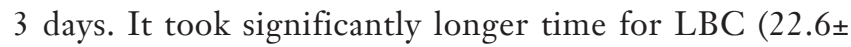
26.0 hours) to be sent to the emergency room than non-LBC $(4.1 \pm 8.5$ hours) $(\mathrm{P}<0.001)$ (Table 1 and Figure $2 C)$. Twentythree $(42.6 \%)$ LBC compared with $3(7.1 \%)$ non-LBC had PHT $>24 \mathrm{~h}(\mathrm{P}<0.001)$. All children with PHT >24 h had endophthalmitis at presentation. The percentages of PHT $>24$ h in children with endophthalmitis were $74.2 \%$ $(23 / 31)$ in the LBC group and $11.1 \%(3 / 27)$ in the nonLBC group $(\mathrm{P}<0.001)$.

At the end of follow up, $\mathrm{LBC}$ received $1.8 \pm 0.7$ vitrectomies (1 to 3 PPVs) and 30 children (55.6\%) received silicone oil tamponade. Thirty-nine (72.2\%) LBC had cataract removal and 26 (66.7\%) had IOL implantation. Non-LBC received $1.3 \pm 0.6$ vitrectomies ( 1 to $3 \mathrm{PPVs}$ ) and 9 children $(21.4 \%)$ received silicone oil tamponade. Twenty-six (61.9\%) non-LBC had cataract removal and $15(57.7 \%)$ had IOL implantation. Compared with non- 


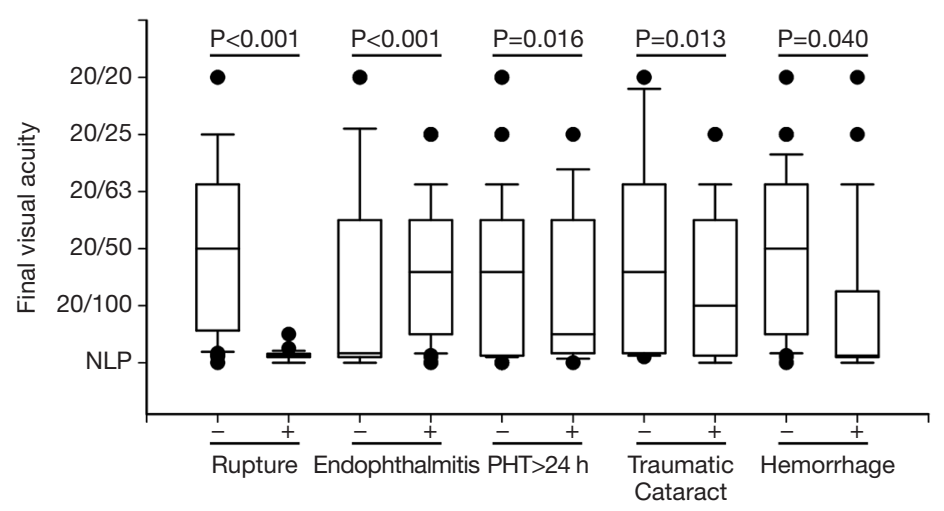

Figure 1 Preoperative factors correlated with visual prognosis. Rupture of the eyeball $(\mathrm{P}<0.001)$, endophthalmitis $(\mathrm{P}<0.001)$, primary hospitalization time over 24 hours $(\mathrm{PHT}>24 \mathrm{~h})(\mathrm{P}=0.016)$, traumatic cataract $(\mathrm{P}=0.013)$, and vitreous hemorrhage $(\mathrm{P}=0.040)$ were correlated with poorer final visual acuity. NLP, no light perception; PHT, primary hospitalization time.

A

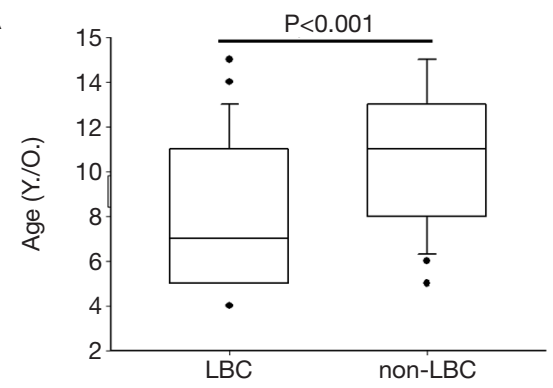

C

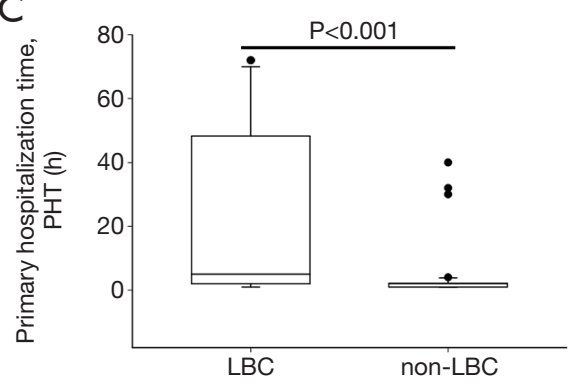

B

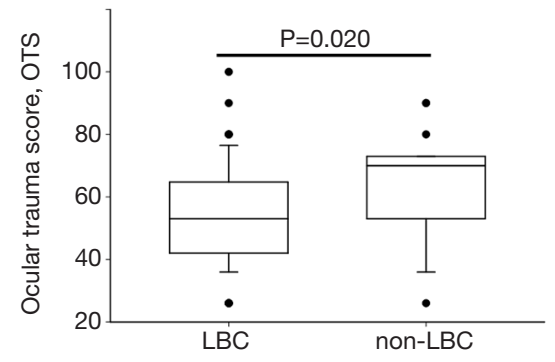

D

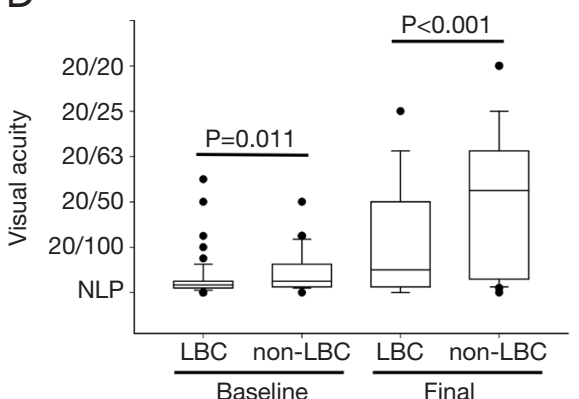

Figure 2 Comparison between LBC and non-LBC. Compared with non-LBC, LBC were significantly younger (P<0.001) (A), had lower OTS scores $(\mathrm{P}=0.020)(\mathrm{B})$, had longer primary hospitalization time $(\mathrm{P}<0.001)(\mathrm{C})$, and worse baseline $(\mathrm{P}=0.011)$ and final visual acuity $(\mathrm{P}<0.001)(\mathrm{D})$. LBC, left-behind children; non-LBC, non-left-behind children.

LBC, LBC required more vitrectomies $(\mathrm{P}=0.009)$ and more silicone oil tamponade $(\mathrm{P}=0.001)$. Cataract surgery and $\mathrm{IOL}$ implantation were not different between the 2 groups.

Injury sources are summarized in Table 2. In total, $66(68.8 \%)$ children were injured by adult instruments, including $43(79.6 \%)$ LBC and 23 (54.8\%) non-LBC. LBC were significantly more likely to be injured by adult instruments $(\mathrm{P}=0.009)$. The incidence of IOFB (26 children in total) was significantly higher for children's instrumentinduced injury ( 15 children, $50.0 \%$ ) than for adult instrument-induced injury (11 children, $16.7 \%)(\mathrm{P}=0.001)$. Pencils were the major injury source for IOFB (14 cases, $53.8 \%)$. No difference was found between the 2 injury sources in terms of endophthalmitis $(\mathrm{P}=0.159)$, retinal 
Table 1 General information between LBC and non-LBC

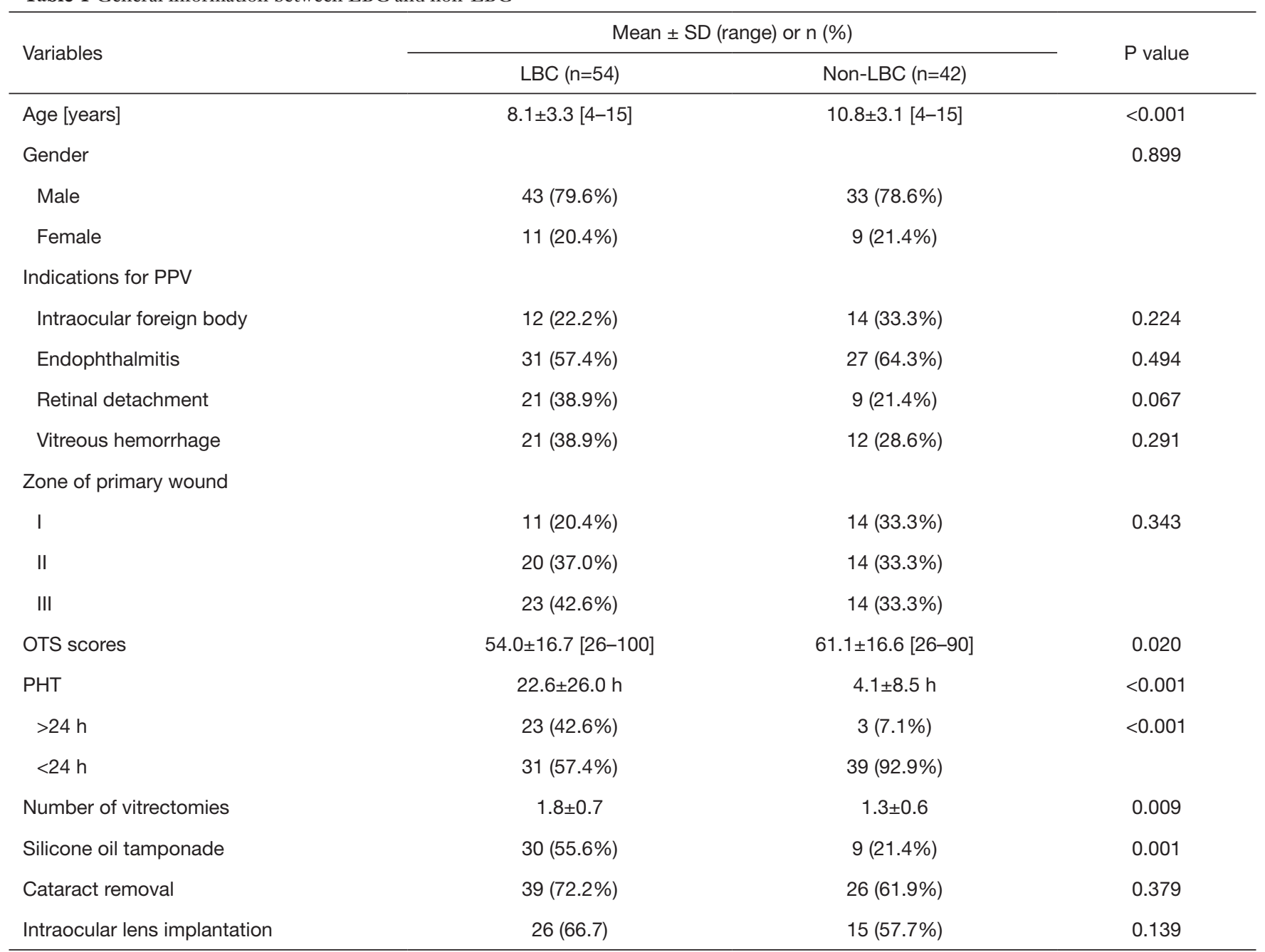

LBC, left-behind children; non-LBC, non-left-behind children; PPV, pars plana vitrectomy; OTS, ocular trauma score; PHT, primary hospitalization time.

detachment $(\mathrm{P}=0.109)$, vitreous hemorrhage $(\mathrm{P}=0.750)$, OTS scores $(\mathrm{P}=0.147)$, final VA $(\mathrm{P}=0.424)$, $\mathrm{PHT}>24 \mathrm{~h}$ $(\mathrm{P}=0.122)$, and traumatic cataract $(\mathrm{P}=0.119)$.

Baseline and final VAs are summarized in Table 3. Compared with baseline VA, VAs were significantly improved in both LBC $(\mathrm{P}<0.001)$ and non-LBC $(\mathrm{P}<0.001)$. Non-LBC had significantly better baseline VA $(\mathrm{P}=0.011)$ and final VA $(\mathrm{P}<0.001)$ (Figure $2 D)$. Final VAs were significantly correlated with baseline VA in both the LBC $(\mathrm{P}<0.001)$ and non-LBC groups $(\mathrm{P}=0.002)$.

Of all the patients, the 3 most common injury sources were pencils (20 cases, $20.8 \%$ ), knives (11 cases, $11.5 \%$ ), and iron wire (7 cases, $7.3 \%$ ) (Figure 3). In LBC, the 3 most common injury sources were iron wire (6 cases, $11.1 \%)$, pencils ( 6 cases, $11.1 \%$ ), and knives ( 5 cases, $9.3 \%$ ). In non-LBC, the 3 most common injury sources were pencils (14 cases, $33.3 \%)$, knives ( 6 cases, 14.3 ), and scissors (4 cases, $9.5 \%$ ).

\section{Discussion}

In this study, compared with non-LBC, LBC suffered more severe injuries (lower OTS scores), had longer PHT, required more vitrectomies, and had a higher rate of silicone oil tamponade. LBC also had worse visual prognosis.

The OTS evaluates ocular trauma by analyzing several baseline factors including VA, eyeball rupture, endophthalmitis, retinal detachment, and relative afferent 
Table 2 Injury sources between LBC and non-LBC

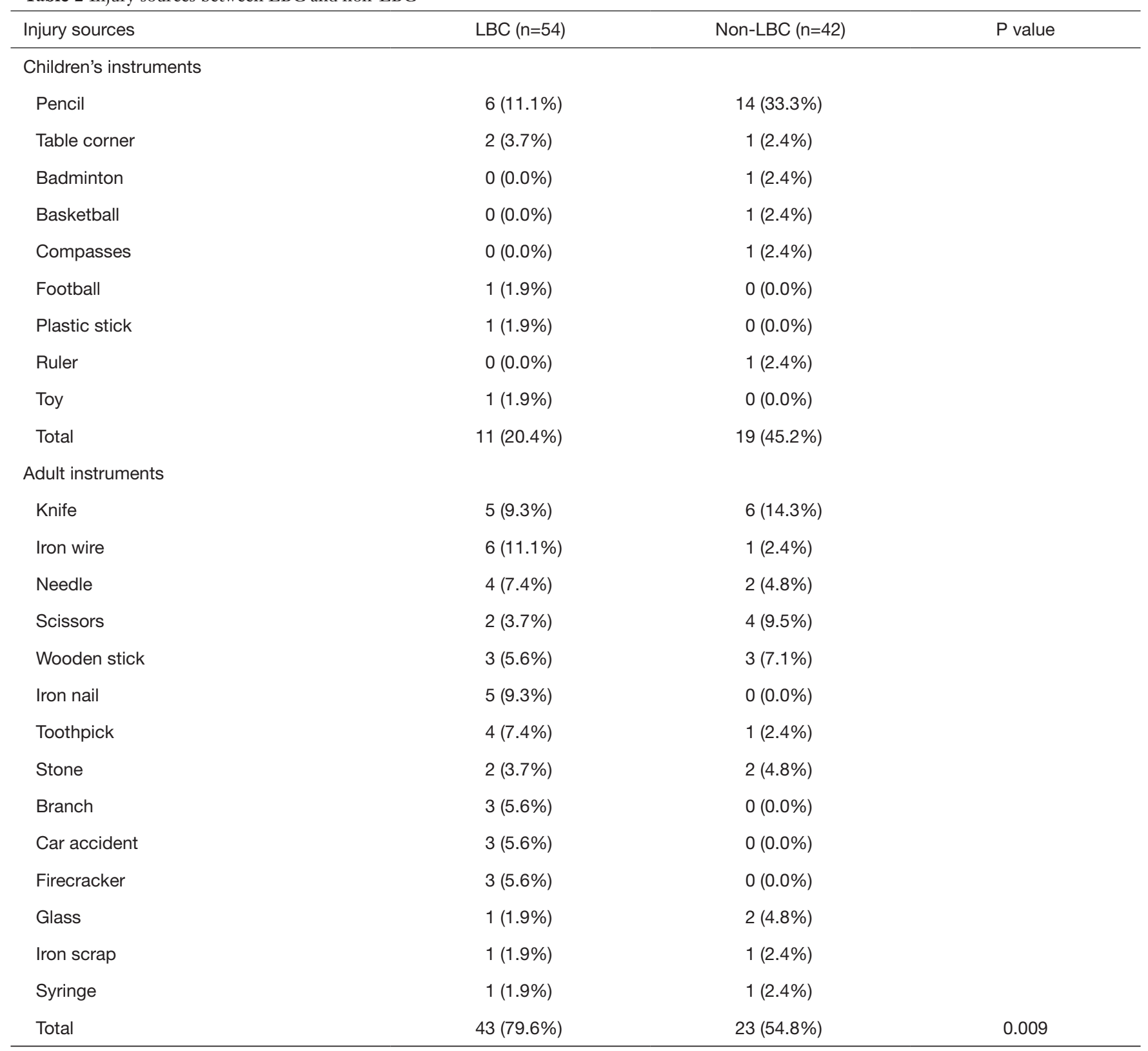

LBC, left-behind children; Non-LBC, non-left-behind children.

pupillary defect (RAPD) (14). A higher OTS score always predicts better visual prognosis (14-17). Similarly, our results suggested that both OTS scores and grades were predictive markers of final VA. Diseases such as eyeball rupture, endophthalmitis, or vitreous hemorrhage were independent factors predisposing patients to poor visual recovery (Figure 1). Another system, the pediatric penetrating ocular trauma score (POTS) (18), was introduced for children whose baseline VAs or RAPD could not be obtained. Children in this study were 4 to 15 years old. Confrontation with the 'white coat' probably made some children scared and uncooperative. They were placed in a quiet room with their guardians until they calmed down and cooperated with the examination. We tried to obtain preoperative VA and RAPD of all children. OTS was a reliable prognostic tool for pediatric open globe injury (OGI) (19).

In the present study, it took significantly more time 
Table 3 Baseline and final visual acuities between LBC and non-LBC

\begin{tabular}{|c|c|c|c|c|c|c|}
\hline Final VA & \multicolumn{6}{|c|}{ Baseline visual acuity, LBC, $\mathrm{n}(\%) /$ non-LBC, $\mathrm{n}(\%)$} \\
\hline $20 / 40$ or better & $0 / 0$ & $1(1.9 \%) / 5(11.9 \%)$ & $6(11.1 \%) / 4(9.5 \%)$ & $4(7.4 \%) / 12(28.6 \%)$ & $1(1.9 \%) / 0$ & $12(22.2 \%) / 21(50.0 \%)$ \\
\hline $20 / 200-20 / 50$ & $0 / 0$ & $7(13.0 \%) / 2(4.8 \%)$ & $6(11.1 \%) / 2(4.8 \%)$ & $5(9.3 \%) / 6(14.3 \%)$ & $0 / 0$ & $18(33.3 \%) / 10(23.8 \%)$ \\
\hline $1 / 200-19 / 200$ & $1(1.9 \%) / 0$ & $3(5.6 \%) / 3(7.1 \%)$ & $3(7.1 \%) / 2(4.8 \%)$ & $0 / 0$ & $0 / 0$ & $7(13.0 \%) / 5(11.9 \%)$ \\
\hline NLP & $2(3.7 \%) / 0$ & $4(7.4 \%) / 1(2.4 \%)$ & $0 / 0$ & $0 / 0$ & $0 / 0$ & $6(11.1 \%) / 1(2.4 \%)$ \\
\hline Total & $5(9.3 \%) / 1(2.4 \%)$ & $21(38.9 \%) / 13(31.0 \%)$ & $18(33.3 \%) / 10(23.8 \%)$ & $9(16.7 \%) / 18(42.9 \%)$ & $1(1.9 \%) / 0$ & $54 / 42$ \\
\hline
\end{tabular}

VA, visual acuity; LBC, left-behind children; Non-LBC, non-left-behind children; NLP, no light perception; LP, light perception; HM, hand motions.

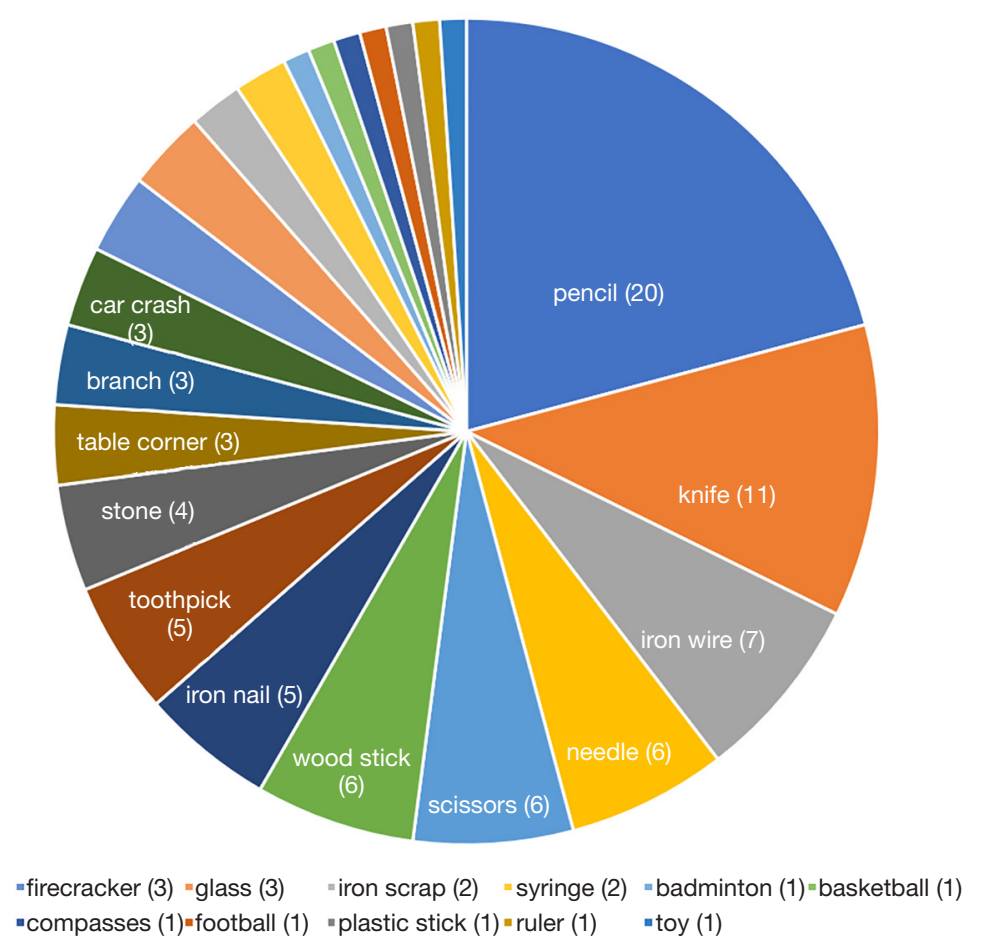

Figure 3 Sector graph of injury sources. Composition of injury sources in all the patients. Of all the patients, the 3 most common injury sources were pencils (20 cases, $20.8 \%$ ), knives (11 cases, $11.5 \%$ ), and iron wire (7 cases, $7.3 \%$ ).

for $\mathrm{LBC}$ to reach the emergency room after injuries than non-LBC (22.6 versus 4.1 hours). Twenty-three (42.6\%) LBC compared with 3 (7.1\%) non-LBC had PHT over 24 hours. At least 3 causes may explain why LBC had longer PHT. (I) Age: LBC in this study were younger and might be reluctant or unable to tell their guardians about the injury soon after they were hurt. (II) Supervision: negligence of the caregivers might be another cause of delayed hospitalization. Families of LBC were incomplete and provided inadequate parental supervision (20). Initial detection of the injury by the caregivers might be delayed. (III) Place of residence: in this study, LBC came from remote areas. It took them hours or even days to get to our hospital. Delayed hospitalization was correlated with poorer 
visual prognosis (Figure 1), indicating the importance of early treatment for OGI children.

The association between delayed repair and posttraumatic endophthalmitis is still controversial. Schmidseder et al. (21) suggested that delayed repair and delayed systemic antibiotic therapy were 2 risk factors for traumatic endophthalmitis. However, Thompson et al. (22) found that this trend did not reach significance. In this study, all children with PHT $>24$ h presented with endophthalmitis and had poorer final VA. Despite that post-traumatic endophthalmitis is a multifactorial disease (including length of wounds, virulence of microorganisms, and individual immunity etc.), we strongly recommended prompt repair of the wound and application of antibiotics in cases with endophthalmitis.

Over half of our patients were injured by adult instruments (Table 2). Sharp instruments, such as iron wires, knives, needles, scissors, iron nails etc., are tools for adults. Curious children might play with these dangerous tools and accidentally hurt themselves or their playmates. LBC were much younger and had less safety consciousness than nonLBC. Hence, they were more likely to be injured by adult instruments. These injuries could have most likely been avoided if the caregivers properly kept these dangerous tools in safe places away from the children.

We also found that pencils accounted for the greatest number of injuries (20 cases, 20.8\%) (Table 2 and Figure 3) and IOFB cases (14 cases, $53.8 \%$ ). The role of writing devices in pediatric eye injury has also been addressed by other researchers $(23,24)$. Unlike adult instruments, it is impractical to simply deprive children of writing devices. For ophthalmologists, penetrating eye injury should be highly suspected when confronting a child injured by a writing instrument. It is necessary to educate caregivers/ parents, children, and educational staff about the potential dangers of the seemingly innocuous writing devices. Children should be taught to correctly use the stationary, especially those with sharp edges or pointed ends.

Taken together, the prognosis of pediatric OGI was worse in LBC than in non-LBC. It is necessary to find effective interventions to improve the guardianship of LBC. Many tragedies may be avoided if adult instruments are properly stored and if children are educated to properly use writing devices.

\section{Acknowledgments}

Funding: This work has been supported by the National Natural Science Foundation of China (No. 81700851), the Shanghai Key Laboratory of Visual Impairment and Restoration (Fudan University, Shanghai 200031, China), by a grant from Science and Technology Commission of Shanghai Municipality (16411953700), and by a grant from Shanghai Hospital Development Center (No. SHDC12016116). The funding organizations had no role in the design or conduct of this research.

\section{Footnote}

Reporting Checklist: The authors have completed the STROBE reporting checklist. Available at http://dx.doi. org/10.21037/tp-21-162

Data Sharing Statement: Available at http://dx.doi. org/10.21037/tp-21-162

Conflicts of Interest: All authors have completed the ICMJE uniform disclosure form (available at http://dx.doi. org/10.21037/tp-21-162). The authors have no conflicts of interest to declare.

Ethical Statement: The authors are accountable for all aspects of the work in ensuring that questions related to the accuracy or integrity of any part of the work are appropriately investigated and resolved. This study was conducted in accordance with the ethical standards stated in the Declaration of Helsinki (as revised in 2013). The study was approved by the Research Ethics Committee of the Eye and ENT Hospital of Fudan University (NO. KJ2009-16). Informed consent for the research was obtained from all the guardians.

Open Access Statement: This is an Open Access article distributed in accordance with the Creative Commons Attribution-NonCommercial-NoDerivs 4.0 International License (CC BY-NC-ND 4.0), which permits the noncommercial replication and distribution of the article with the strict proviso that no changes or edits are made and the original work is properly cited (including links to both the formal publication through the relevant DOI and the license). See: https://creativecommons.org/licenses/by-nc-nd/4.0/.

\section{References}

1. Abbott J, Shah P. The epidemiology and etiology of pediatric ocular trauma. Surv Ophthalmol 2013;58:476-85. 
2. May DR, Kuhn FP, Morris RE, et al. The epidemiology of serious eye injuries from the United States Eye Injury Registry. Graefes Arch Clin Exp Ophthalmol 2000;238:153-7.

3. Strahlman E, Elman M, Daub E, et al. Causes of pediatric eye injuries. A population-based study. Arch Ophthalmol 1990;108:603-6.

4. Rahi JS, Cumberland PM, Peckham CS. Visual function in working-age adults: early life influences and associations with health and social outcomes. Ophthalmology 2009; 116:1866-71.

5. Vinger PF. Injury prevention: where do we go from here? J Am Optom Assoc 1999; 70:87-98.

6. All-China Women's Federation A Study Report on the Situation of Left-behind Children and Migrant Children in Rural and Urban Areas in China. 2013. Available online: (http://acwf.people.com.cn/n/2013/0510/c9901321437965.html).

7. Feng H, Liu J, Wang Y, et al. Sociodemographic correlates of behavioral problems among rural Chinese schoolchildren. Public Health Nurs 2011;28:297-307.

8. Zhou FL, Duan CR. Reviews of studies of left behind children. Popul J 2006;3:60-5.

9. Ma S. China's "left behind" children often suffer health consequences. CMAJ 2010;182:E731-2.

10. Shen M, Gao J, Liang Z, et al. Parental migration patterns and risk of depression and anxiety disorder among rural children aged 10-18 years in China: a cross-sectional study. BMJ Open 2015;5:e007802.

11. Ge Y, Se J, Zhang J. Research on relationship among internet-addiction, personality traits and mental health of urban left-behind children. Glob J Health Sci 2014;7:60-9.

12. Jiang S, Chu J, Li C, et al. Alcohol consumption is higher among left-behind Chinese children whose parents leave rural areas to work. Acta Paediatr 2015;104:1298-304.

13. Pieramici DJ, Sternberg P Jr, Aaberg TM Sr, et al. A system for classifying mechanical injuries of the eye (globe). The Ocular Trauma Classification Group. Am J

Cite this article as: Zhuang X, Jiang R, Xu G, Sun Z. Pediatric open globe injury in left-behind children treated by pars plana vitrectomy in China. Transl Pediatr 2021;10(5):1346-1354. doi: 10.21037/tp-21-162
Ophthalmol 1997;123:820-31.

14. Kuhn F, Maisiak R, Mann L, et al. The Ocular Trauma Score (OTS). Ophthalmol Clin North Am 2002;15:163-5, vi.

15. Cillino S, Casuccio A, Di Pace F, et al. A five-year retrospective study of the epidemiological characteristics and visual outcomes of patients hospitalized for ocular trauma in a Mediterranean area. BMC Ophthalmol 2008;8:6.

16. Knyazer B, Levy J, Rosen S, et al. Prognostic factors in posterior open globe injuries (zone-III injuries). Clin Exp Ophthalmol 2008;36:836-41.

17. Uysal Y, Mutlu FM, Sobaci G. Ocular Trauma Score in childhood open-globe injuries. J Trauma 2008;65:1284-6.

18. Acar U, Tok OY, Acar DE, et al. A new ocular trauma score in pediatric penetrating eye injuries. Eye (Lond) 2011;25:370-4.

19. Zhu L, Wu Z, Dong F, et al. Two kinds of ocular trauma score for paediatric traumatic cataract in penetrating eye injuries. Injury 2015;46:1828-33.

20. Zhong Y, Zhong Z, Pan J, et al. Research on child neglect situation and influential factors of left-behind children and living-with-parents children aged 6-17 year-old in rural areas of two provinces, western China. Zhonghua Yu Fang Yi Xue Za Zhi 2015;49:873-8.

21. Schmidseder E, Mino de Kaspar H, Klauss V, et al. Posttraumatic endophthalmitis after penetrating eye injuries. Risk factors, microbiological diagnosis and functional outcome. Ophthalmologe 1998;95:153-7.

22. Thompson WS, Rubsamen PE, Flynn HW Jr, et al. Endophthalmitis after penetrating trauma. Risk factors and visual acuity outcomes. Ophthalmology 1995;102:1696-701.

23. Kelly SP, Reeves GM. Penetrating eye injuries from writing instruments. Clin Ophthalmol 2012;6:41-4.

24. Tabatabaei SA, Soleimani M, Naderan M, et al. A survey of incidental ocular trauma by pencil and pen. Int J Ophthalmol 2018;11:1668-73.

(English Language Editor: C. Betlazar-Maseh) 